\title{
Bringing Data Analytics to the Design of Optimized Diagnostic Networks in Low- and Middle-Income Countries: Process, Terms and Definitions
}

\author{
Kameko Nichols ${ }^{1,+}$, Sarah J. Girdwood ${ }^{2, *}+{ }^{+}$, , Andrew Inglis ${ }^{3}$, Pascale Ondoa ${ }^{4,5,6}$, Karla Therese L. Sy ${ }^{7,8} \mathbb{D}$, \\ Mariet Benade $^{7}\left(\mathbb{D}\right.$, Aloysius Bingi Tusiime ${ }^{9} \mathbb{D}$, Kekeletso Kao ${ }^{1}$, Sergio Carmona ${ }^{1}$, Heidi Albert ${ }^{10, \ddagger(D)}$ \\ and Brooke E. Nichols $2,7,11, *, \ddagger$ (iD)
}

check for

updates

Citation: Nichols, K.; Girdwood, S.J.;

Inglis, A.; Ondoa, P.; Sy, K.T.L.;

Benade, M.; Tusiime, A.B.; Kao, K.;

Carmona, S.; Albert, H.; et al.

Bringing Data Analytics to the Design of Optimized Diagnostic Networks in Low- and Middle-Income Countries: Process, Terms and Definitions. Diagnostics 2021, 11, 22. https:// doi.org/10.3390/diagnostics 11010022

Received: 30 November 2020 Accepted: 21 December 2020 Published: 24 December 2020

Publisher's Note: MDPI stays neutral with regard to jurisdictional clai$\mathrm{ms}$ in published maps and institutional affiliations.

Copyright: (C) 2020 by the authors. Licensee MDPI, Basel, Switzerland. This article is an open access article distributed under the terms and conditions of the Creative Commons Attribution (CC BY) license (https:// creativecommons.org/licenses/by/ $4.0 /)$.
1 FIND, 1202 Geneva, Switzerland; kameko@thenicholsgroupllc.com (K.N.); kekeletso.kao@finddx.org (K.K.); Sergio.carmona@finddx.org (S.C.)

2 Health Economics and Epidemiology Research Office, Department of Internal Medicine, School of Clinical Medicine, Faculty of Health Sciences, University of the Witwatersrand, Johannesburg 2193, South Africa

3 USAID Global Health Supply Chain Programme, Procurement and Supply Management, International Business Machines, Arlington, VA 22202, USA; Andrew.inglis@ibm.com

4 African Society for Laboratory Medicine, Addis Ababa 5487, Ethiopia; POndoa@aslm.org

5 Amsterdam Institute for Global Health and Development, 1105 BP Amsterdam, The Netherlands

6 Department of Global Health, Amsterdam University Medical Center, 1105 AZ Amsterdam, The Netherlands

7 Department of Global Health, Boston University School of Public Health, Boston, MA 02118, USA; rsy@bu.edu (K.T.L.S.); mbenade@bu.edu (M.B.)

8 Department of Epidemiology, Boston University School of Public Health, Boston, MA 02118, USA

9 USAID Global Health Supply Chain Programme, Procurement and Supply Management, Chemonics International, Arlington, VA 22202, USA; ABingiTusiime@ghsc-psm.org

10 FIND, Cape Town 7925, South Africa; heidi.albert@finddx.org

11 Department of Medical Microbiology, Amsterdam University Medical Center, 1105 AZ Amsterdam, The Netherlands

* Correspondence: sgirdwood@heroza.org (S.J.G.); brooken@bu.edu (B.E.N.); Tel.: +27-71-2276429 (S.J.G.); +1-617-414-1260 (B.E.N.)

+ Equal contribution.

$\ddagger$ Equal contribution.

Abstract: Diagnostics services are an essential component of healthcare systems, advancing universal health coverage and ensuring global health security, but are often unavailable or under-resourced in low- and middle-income (LMIC) countries. Typically, diagnostics are delivered at various tiers of the laboratory network based on population needs, and resource and infrastructure constraints. A diagnostic network additionally incorporates screening and includes point-of-care testing that may occur outside of a laboratory in the community and clinic settings; it also emphasizes the importance of supportive network elements, including specimen referral systems, as being critical for the functioning of the diagnostic network. To date, design and planning of diagnostic networks in LMICs has largely been driven by infectious diseases such as TB and HIV, relying on manual methods and expert consensus, with a limited application of data analytics. Recently, there have been efforts to improve diagnostic network planning, including diagnostic network optimization (DNO). The DNO process involves the collection, mapping, and spatial analysis of baseline data; selection and development of scenarios to model and optimize; and lastly, implementing changes and measuring impact. This review outlines the goals of DNO and steps in the process, and provides clarity on commonly used terms.

Keywords: diagnostic network optimization; data analytics; low- and middle-income countries

\section{Diagnostics: An Essential Health Systems Component}

"Without diagnostics, medicine is blind." [1] Diagnostics are an essential component of healthcare systems and are integral to many clinical decisions in confirming disease; 
monitoring treatment; recognizing complications such as drug resistance; preventing the spread of disease and antimicrobial resistance; and enhancing surveillance for early disease detection and monitoring [2]. Furthermore, the essential role of diagnostics in advancing universal health coverage (UHC) is acknowledged in the 2nd List of Essential In Vitro Diagnostics, and the role of diagnostics to ensure global health security is outlined in the International Health Regulations (IHR) [3,4]. Yet diagnostics are often unavailable, inaccessible, or too costly for patients who need them in low- and middle-income countries (LMICs), and frequently remain overlooked and under-resourced [5,6]. Moreover, where testing capacity is available, it is often underutilized and of variable quality, and result delivery is inconsistent or too lengthy to render it clinically relevant [7].

There are many important considerations for the role of diagnostics in disease detection, such as determining the appropriate setting for a test, whether the tests will be used appropriately, whether the clinical utility of the test is proven in a particular population, and whether the test results will be available in time to inform patient-care decisions or public-health measures. A quick and accurate diagnosis can ensure that the right care and treatment is administered to the patient in time, allowing for a more effective treatment and monitoring. In the case of infectious diseases, including human immunodeficiency virus (HIV) and tuberculosis (TB), patients who remain undiagnosed can also unknowingly transmit infection to others and develop permanent sequelae. Evidence-based optimization of diagnostic services can close the gap on access to diagnostics and bring us closer to achieving UHC and IHR.

\section{The Importance of Diagnostic Networks}

As countries move towards UHC, they should ensure that diagnostic testing is affordable, of high quality and that there is equity in access [8]. One way to ensure availability of diagnostic services to all patients regardless of where they first seek care within the health system would be to place diagnostic testing at every health facility. There are, however, multiple reasons why this is not feasible or advisable. Firstly, not all diagnostic tests are suitable for use at point-of-care or at peripheral health facilities due to skilled human-resource constraints and infrastructure requirements. Secondly, managing and maintaining quality becomes difficult when more testing sites are added and testing is decentralized. This is especially the case when low numbers of tests may be conducted at individual health facilities, driving up the cost per test. Further, a significant financial investment would be required to establish and maintain the required infrastructure and equipment. In the majority of LMICs these budgets are severely constrained and have other competing priorities.

Instead, to address these challenges, diagnostic services are made available through an integrated, tiered national laboratory network where the various tiers are determined by their diagnostic test menus based on population testing needs, infrastructure requirements, and resource constraints $[8,9]$. The purpose of this tiered national laboratory network is to provide integrated diagnostic services for clinical and public health systems [8]. Next, specimen referral systems link patients and/or samples at peripheral health facilities to laboratories or testing sites within the network, such that service offerings are broadened beyond what is offered onsite and tests are performed at the most appropriate tier [10-13].

A diagnostics network is the interconnected system that is used to yield a diagnosis either within a clinical or public-health setting. Although the terms "diagnostic network" and "laboratory network" are often used interchangeably, we distinguish between the two, with a diagnostic network going beyond the definition of the laboratory network to encompass a more patient-centered, coordinated network where tests are accessible, accurate and adaptable, and results are produced quickly [14]. A diagnostic network includes rapid diagnostic and point-of-care testing that may occur outside of a laboratory in the community and clinic settings; it also elevates the supportive role of the specimen referral system to a critical role for the functioning of the diagnostic network. An illustrative example of a tiered national diagnostic network is found in Figure 1 below. 


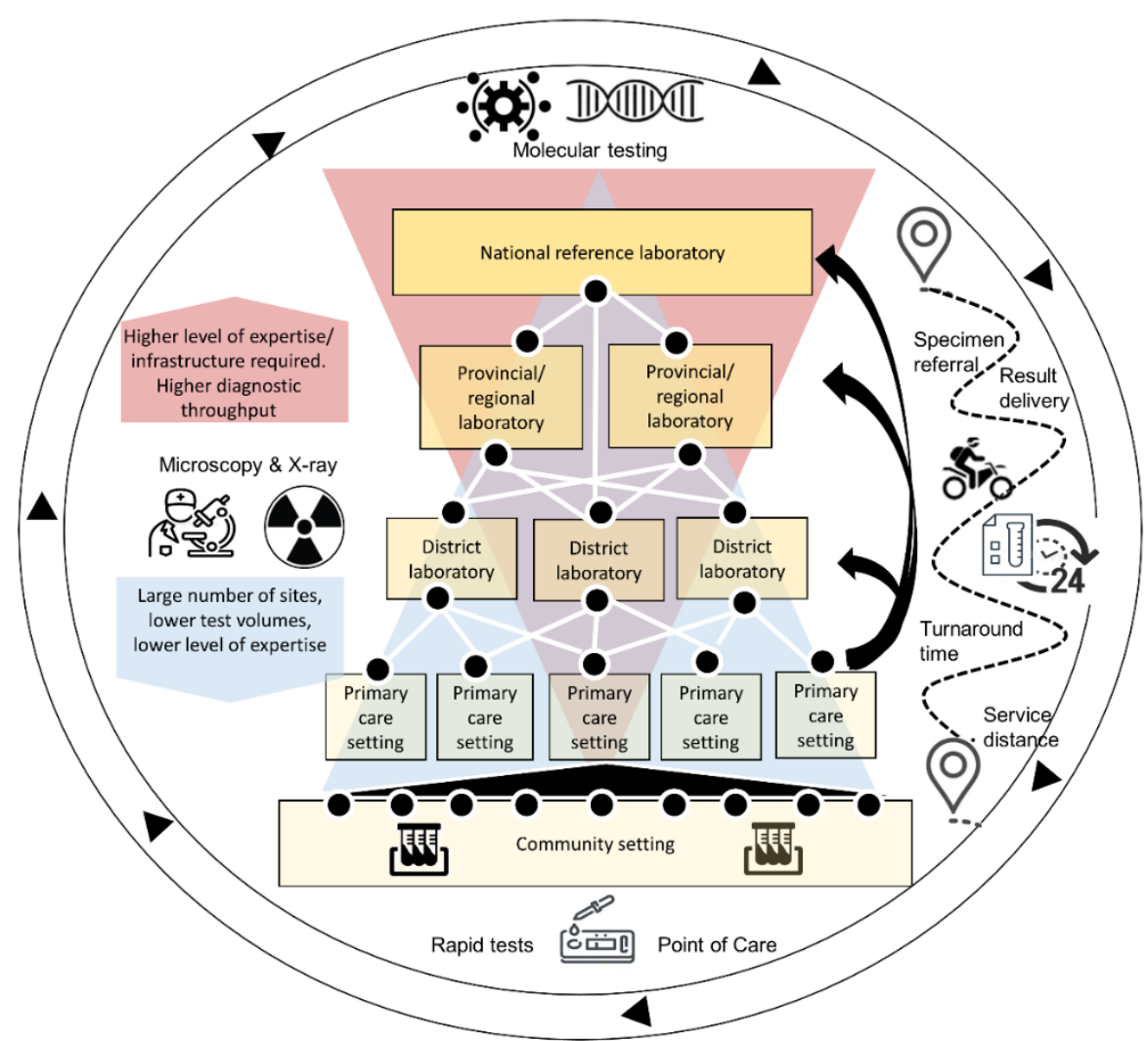

Figure 1. Example of a national, interconnected diagnostic network: At the higher levels of the network there are fewer sites, higher required levels of expertise, and high-throughput diagnostics such as polymerase chain reaction tests for viral detection. At the most basic levels of the network (e.g., clinic and community settings), this includes a large number of sites and rapid diagnostic tests and point-of-care; all functions are supported by a specimen referral system that ensures timely specimen referral and result delivery for all sites, regardless of service distance.

The design and planning of diagnostic networks to date has relied mostly on manual methods and expert consensus, with a limited application of data analytics. However, this approach is not ideal to analyze complex and multivariate datasets, including demand for services, locations and capacity, as well as exploring the current baseline state and future potential scenarios under a range of applied constraints, including costs, allowable service distances, and the turnaround time of results. More recently, there have been numerous efforts to improve this methodology, and thus the term "diagnostic network optimization" (DNO) and related terms are used frequently. When these terms are used, they are used with a wide range of definitions. As such, it is useful to define terms used around this type of network analysis. Furthermore, it is important to also understand what questions we can answer with DNO, and what it can do to strengthen diagnosis and national health systems in the context of UHC and the requirements of IHR. The terms are introduced and explained throughout the text, and then each term is defined in more detail in Table 1. 
Table 1. Terms and definitions related to diagnostic network design and optimization. Terms highlighted in green address, "What is a diagnostic network and how does it compare to a laboratory network?"; items in blue address, "How can we improve the diagnostic network through analysis?"; and terms in yellow address, "What are the objectives of a diagnostic network? How do we know if it is performing well?".

\begin{tabular}{|c|c|}
\hline Term & Specific Definition as Related to Diagnostics Network Optimization \\
\hline $\begin{array}{l}\text { Tiered laboratory } \\
\text { network }\end{array}$ & $\begin{array}{l}\text { An integrated system of laboratories organized in tiers aligned with the public health delivery } \\
\text { system of the country. The tiers are determined by their test menus and functions, and a specimen } \\
\text { referral network ensures tests are performed at the most appropriate level of the tiered system. }\end{array}$ \\
\hline Diagnostic network & $\begin{array}{l}\text { "Diagnostic" and "laboratory" are often used interchangeably with "network" but "diagnostic } \\
\text { network" includes all testing sites and instruments within a laboratory network as well as testing } \\
\text { sites and instruments that fall outside a laboratory setting-e.g., rapid diagnostic- and point-of-care } \\
\text { tests, which can be delivered in community and clinic settings. It allows for inclusion of } \\
\text { non-laboratory testing that is part of diagnostics process, i.e., screening, radiology, etc. The role of the } \\
\text { specimen referral network is elevated. }\end{array}$ \\
\hline $\begin{array}{c}\text { Specimen referral } \\
\text { network }\end{array}$ & $\begin{array}{l}\text { An interconnected group of specimen referral systems, which comprise all components and processes } \\
\text { required for patient specimens to be tested at a location that differs from where the specimen was } \\
\text { collected. }\end{array}$ \\
\hline $\begin{array}{c}\text { Diagnostic network } \\
\text { design }\end{array}$ & $\begin{array}{l}\text { Uses location data, testing demand and capacity and referral linkage data on collection points and } \\
\text { testing facilities to build a model of the current state/baseline of the network and then using that to } \\
\text { help identify gaps and opportunities and improve the network to achieve desired objectives i.e., } \\
\text { improved access or reduced cost. }\end{array}$ \\
\hline $\begin{array}{l}\text { Diagnostic network } \\
\text { optimization (DNO) }\end{array}$ & $\begin{array}{l}\text { Optimization maximizes or minimizes an objective, by changing the variables under control subject } \\
\text { to certain constraints. In the context of diagnostic networks, it is a computerized analytical process } \\
\text { that designs a single diagnostic network based on objectives (minimizing costs, maximizing access, } \\
\text { minimizing turnaround time) and variables (transport, device placement) within given constraints } \\
\text { (capacity, costs); the best setting of variables that meets the objectives. Excluded from the definition } \\
\text { are other analyses or interventions aimed at strengthening laboratory systems that do not incorporate } \\
\text { these aspects. }\end{array}$ \\
\hline Constraints & $\begin{array}{l}\text { Limits placed on variables in the process of optimization. In DNO, constraints could include capping } \\
\text { the total number of instruments, number of testing sites, actual equipment capacity, total costs, or } \\
\text { ability to refer samples across administrative boundaries within a country. }\end{array}$ \\
\hline Route optimization & $\begin{array}{l}\text { Route optimization is the process of determining the most efficient route. It is more complex than } \\
\text { simply finding the shortest path between two points. It needs to include all relevant factors such as } \\
\text { the number and location of all the required stops on the route. This is why route optimization is } \\
\text { mostly performed by computer algorithms that can quickly narrow down the options. Route } \\
\text { optimization software can quickly test multiple 'what-if' scenarios to help fleets review the costs of } \\
\text { different route options and resource availability, but within a given set of constraints. This is also } \\
\text { known as vehicle route optimization. }\end{array}$ \\
\hline Collection points & $\begin{array}{c}\text { The physical location where specimens are collected from an individual requiring a diagnostic test. } \\
\text { These may also be referred to as referring facilities or spokes. }\end{array}$ \\
\hline Hubs & $\begin{array}{l}\text { The physical location where specimens may be pooled after leaving the collection point. The hub } \\
\text { may offer certain testing onsite or may only serve as an intermediate pooling and processing point } \\
\text { (i.e., for centrifuging) for specimens before they reach the testing facility. Hubs may also offer quality } \\
\text { checks and documentation points for specimens. }\end{array}$ \\
\hline Testing facilities & $\begin{array}{l}\text { The physical location where the specimens are processed. If the diagnostic test is offered onsite, then } \\
\text { this could be the same physical location as the collection site. If testing occurs offsite, then this would } \\
\text { be the physical location of the laboratory. }\end{array}$ \\
\hline Baseline or Current state & $\begin{array}{l}\text { Current status of the diagnostic network, including current levels of accessibility, turnaround times, } \\
\text { interconnectedness, collection points, and testing facilities. It is a fixed point of reference that is used } \\
\text { for comparison purposes. }\end{array}$ \\
\hline
\end{tabular}


Table 1. Cont.

\begin{tabular}{|c|c|}
\hline Term & Specific Definition as Related to Diagnostics Network Optimization \\
\hline Mapping & $\begin{array}{l}\text { Refers to the geospatial mapping of the location data for collection points and testing facilities } \\
\text { supplemented by other diagnostic network data, namely testing demand, testing capacity and } \\
\text { referral linkages between locations; however, importantly, mapping is not synonymous with } \\
\text { "network optimization." }\end{array}$ \\
\hline Scenarios & $\begin{array}{l}\text { Scenarios are potential changes that can be made to the baseline or current state and are created } \\
\text { through a subjective exercise to discuss "What if" (in terms of inputs or variables such as capacity or } \\
\text { demand) and decide which to explore; this process is informed by the baseline situation (including } \\
\text { mapping, spatial analysis, costs). }\end{array}$ \\
\hline Scenario analysis & $\begin{array}{l}\text { The process or technique of testing potential changes to the system to consider the potential } \\
\text { outcomes and implications of a change to assist or improve decision making. This answers the } \\
\text { question of "what if" and allows for comparison with the baseline or current state. }\end{array}$ \\
\hline $\begin{array}{l}\text { Vertical systems or } \\
\text { programs }\end{array}$ & $\begin{array}{l}\text { A vertical system or program only focuses on one disease or one area. For example, a vertical } \\
\text { specimen referral system would only refer specimens for one disease program (such as for HIV, or for } \\
\text { TB). The primary advantage of a vertical system is that the needs of an individual disease program is } \\
\text { prioritized. The primary disadvantage is potential inefficiencies introduced by having multiple } \\
\text { vertical systems serving one disease each [15]. }\end{array}$ \\
\hline $\begin{array}{l}\text { Integrated systems or } \\
\text { programs }\end{array}$ & $\begin{array}{l}\text { An integrated system or program focuses on multiple diseases or areas. Integration can happen at } \\
\text { multiple levels of the health system or in different areas. For example, a specimen referral system that } \\
\text { serves primary health facilities and connects them to district level may carry more than one } \\
\text { specimen-type for more than one disease area (this will also depend on the co-location of pickup and } \\
\text { delivery points). Integration must be done to ensure the goals and needs for all programs are met } \\
\text { and optimization for one program does not negatively impact other programs. Another type of } \\
\text { integration is for testing (see testing integration). }\end{array}$ \\
\hline Testing integration & $\begin{array}{l}\text { Testing integration or multiplexing uses the same technology (also known as polyvalent testing } \\
\text { platforms or multianalyte analyzers) for several assays and/or across diseases. It can lead to more } \\
\text { efficient and cost-effective testing services. Further, diagnostic integration can help to simplify and } \\
\text { streamline other systems, such as specimen referral, human resources and quality assurance [16]. }\end{array}$ \\
\hline Coverage & $\begin{array}{c}\text { Health service coverage is defined as the extent to which target populations receive health } \\
\text { interventions. For diagnostic services coverage, this relates to geographic coverage as well as } \\
\text { targeted coverage of key populations such as people living with HIV (PLHIV), children, miners, } \\
\text { other vulnerable populations, etc [17]. }\end{array}$ \\
\hline Availability & $\begin{array}{l}\text { Availability is a component of physical access-in order for a service to be accessible, it must first be } \\
\text { available. Availability is centered around testing (which requires capacity and capability) and referral } \\
\text { systems (the tests available either onsite or via a referral system) [18]. }\end{array}$ \\
\hline Access & $\begin{array}{l}\text { The focus of 'access' for DNO is on physical accessibility of diagnostics, and what proportion of } \\
\text { individuals can access a diagnostic if required within a given health system. }\end{array}$ \\
\hline Turnaround time & $\begin{array}{l}\text { The time elapsed between collection of a specimen from a client and return of the results to the } \\
\text { facility or client, and, in some cases, to the time of clinical intervention based on that result. If these } \\
\text { data are unavailable, other intermediary turnaround times are used, e.g., testing turnaround time. In } \\
\text { DNO, turnaround time refers to the time that the specimen is picked up to the time that the result is } \\
\text { returned to the requesting facility [19]. }\end{array}$ \\
\hline Efficiency & $\begin{array}{l}\text { Efficiency concerns the relationship between resource inputs (e.g., costs) and intermediate or final } \\
\text { health outcomes. There are two areas of efficiency for DNO: (1) cost outcomes-the ratio of financial } \\
\text { resources consumed (total cost of the diagnostic network) to the health outcome (the valued health } \\
\text { system output that is created by the cost input-for example, number of correct tests results returned } \\
\text { within a time period, etc.)) and (2) equipment utilization. Efficiency must be balanced with access } \\
\text { and other effectiveness measures such as turnaround time. }\end{array}$ \\
\hline $\begin{array}{l}\text { Maximum equipment } \\
\text { testing capacity }\end{array}$ & $\begin{array}{l}\text { Maximum capacity, or theoretical capacity, does not take the actual testing environment into } \\
\text { consideration-it is the manufacturer's calculation of the instrument capacity. This may be used as } \\
\text { the denominator in the utilization calculation. }\end{array}$ \\
\hline
\end{tabular}


Table 1. Cont.

\begin{tabular}{|c|c|}
\hline Term & Specific Definition as Related to Diagnostics Network Optimization \\
\hline $\begin{array}{l}\text { Actual equipment testing } \\
\text { capacity }\end{array}$ & $\begin{array}{l}\text { Actual available equipment capacity takes into consideration human resource availability and } \\
\text { capacity, site conditions, and thus it is usually less than theoretical maximum capacity. It may be used } \\
\text { as the denominator in the utilization calculation. }\end{array}$ \\
\hline Utilization & $\begin{array}{l}\text { The level of usage of equipment within a set time window compared to the maximum theoretical } \\
\text { device testing capacity and/or actual available device testing capacity within the same period, } \\
\text { e.g., actual number of tests conducted as a proportion of the total number of tests that could have } \\
\text { been conducted on a particular device. }\end{array}$ \\
\hline Equity & $\begin{array}{l}\text { Equity in health refers to fairness in the distribution of healthcare resources and outcomes amongst } \\
\text { population groups defined socially, economically, demographically or geographically. As it relates to } \\
\text { DNO, equity is a measure of the distribution and fairness of geographical access. Equity } \\
\text { considerations are a competing dimension to efficiency considerations which can be explicitly } \\
\text { examined through DNO. For example, whilst it might not be cost-effective to provide diagnostic } \\
\text { access to certain hard-to-reach populations, it might be important if decision-makers value equity. }\end{array}$ \\
\hline Quality & $\begin{array}{l}\text { This refers to the quality of the diagnostic services in terms of the probability that the test result is } \\
\text { accurate and reproducible and is a broader concept compared to external quality assessment. Quality } \\
\text { starts with selecting and procuring the right tests produced under good manufacturing practice, } \\
\text { validated as appropriate for the population and settings of intended use. Next, it is a function of the } \\
\text { specimen type and collection, transport, and whether testing is done by trained and competent staff, } \\
\text { as well as the level of quality-assurance (both internal and external, including proficiency testing) } \\
\text { during all steps of the process. }\end{array}$ \\
\hline Adaptability & $\begin{array}{l}\text { Adaptability measures the ability of a diagnostic network to adjust to changing needs within the } \\
\text { diagnostic network, whether as a result of an addition of a disease program, new technology, } \\
\text { specimen type or disease outbreak. }\end{array}$ \\
\hline
\end{tabular}

\section{Diagnostic Network Optimization}

One way to inform improvement of the broader diagnostic network for a country is to conduct diagnostic network design and optimization. DNO matches testing demand and capacity (e.g., through device placement and test-demand referral) to increase access, improve efficiency, and develop routing for the specimen referral network [7]. It is an analytical process that selects the best network configuration from available alternatives based on objectives (minimizing costs, maximizing access, minimizing turnaround time) and variables (transport, device placement, etc.) within given constraints; in other words, a mathematical calculation solving for the optimal combination of variables with the goal of achieving the objectives [20]. Diagnostic network design can help highlight the tradeoffs that exist between the different objectives and constraints and why it is important to be clear about the objectives of the DNO upfront during the design process. For example, while it might make sense to place point-of-care HIV viral-load devices at every health facility in order to maximize population coverage, it would not be the optimal solution if the system is constrained by costs. Alternatively, while it might not be cost-effective to place point-of-care HIV viral-load devices at low-volume, hard-to-reach facilities, if the model is maximizing access (or equity in access), these competing dimensions would need to be balanced. The design process helps reveal these tradeoffs between efficiency and effectiveness.

To date, the majority of DNO work in LMICs has been focused on the infectious disease space. This is driven in part by the investment in viral-load monitoring for patients on antiretroviral treatment for HIV infection, early infant diagnosis for infants born to HIVpositive mothers, and TB diagnosis [7,20-24]. Given the siloed nature of funding, the vast majority of DNO exercises have been vertical in nature or disease-specific, likely leading to inefficiencies. Instead of siloed DNOs, integration across a full basket of essential diagnostics is possible and is especially critical when integration across test devices and specimen-referral systems results in efficiencies. The basket of essential diagnostics will differ from country to country, but should satisfy the priority healthcare needs of the population and be selected based on disease prevalence, public health relevance, and 
evidence of utility, accuracy, and comparative cost-effectiveness [3]. The selection of the essential diagnostics is not explicitly covered in network optimization.

Although a computer model or software is not required for a simple spatial analysis, for our purposes we are limiting network design and optimization to sophisticated processes that are done with the aid of computer software that enables integration of Geographic Information System (GIS) data, health-service capacity, and diagnostic demand to prioritize and weigh trade-offs among the various priorities and objectives. While a network optimization approach has been used in improving supply chains in the corporate sector, application to optimizing the design of diagnostic networks and specimen referral is relatively new in LMICs [25]. Some examples of the use of DNO in the field include the use of mathematical modeling linked with GIS software in Zambia and South Africa, as well as the use of specific software (Llamasoft's Supply Chain Guru) in Lesotho, Kenya, and the Philippines [20-22,26-31]. The focus of DNO in Zambia has been on the optimization of viral-load access and has seen the number of viral tests performed double within a year $[21,22,27,32]$. DNO exercises in South Africa have optimized the diagnostic network for CD4 testing, placement of viral-load point-of-care, and also optimized the specimen routing for multiple diagnostics [26,33,34]. In Lesotho, Kenya, and the Philippines, DNO has informed instrument placement and specimen referral within the TB diagnostic network [20,28-30]. The need for an accessible, easy-to-use software focused on diagnostic networks was identified following work in several countries using proprietary tools, and development and piloting of such a tool (OptiDx) is now underway [35-37].

The DNO process encompasses the following activities: geographic mapping and baseline model creation, scenario creation and analysis, network optimization, and evaluation.

\subsection{Geographic Mapping and Creation of the Current State Network Model}

The first step in the optimization process is the collection of baseline data and geographic mapping of the current diagnostic network. Location data for facilities (collection points, testing facilities, and hubs) can be visualized on a geographic map and overlaid with additional diagnostic network data, including: (1) demand for the respective diagnostic; (2) capacity of testing (based on human resources and equipment); and (3) referral linkages (which collection point refers specimens to which testing facility through which hub(s), if necessary). Once the data are mapped, analysis of the spatial relationship between populations (demand), collection points, and testing facilities, as well as device utilization and cost allows identification of gaps in the current diagnostic network in terms of demand, capacity, and coverage, and opportunities for improvement that can be explored in alternative scenarios. This analysis of the diagnostic network exposes the different trade-offs that decision-makers might need to consider.

\subsection{Scenario Development}

Once the current network state is mapped and spatially analyzed, alternative scenarios are created to test out various future state configurations for the diagnostic network [20]. These scenarios should be discussed with key stakeholders, reflect stakeholder priorities, and address key questions that can be evaluated through scenario analysis, for example: "What proportion of HIV viral-load results can be returned within an agreed-upon turnaround time?" or "How will device capacity and placement need to evolve to meet projected TB testing demand?" or "What is the optimal mix of devices to fill remaining capacity gaps?" or "In serving demand and turnaround time for people living with HIV, how can we ensure demand for other indications is not negatively impacted?" Once a subset of prioritized scenarios is decided upon, a model will be created for each scenario. The use of scenario analysis aims to provide a representation of the defined scenarios and their impact on the diagnostic network. After the models are created for each scenario, network optimization can begin. A set of outputs, common across all scenarios, can then be compared. 


\subsection{Measuring Success of Diagnostic Network Optimization}

It is important to identify how diagnostic network design and optimization might improve the network and to choose indicators that measure this potential improvement. The analytical processes of design and optimization aim to improve the effectiveness, efficiency, and adaptability of the diagnostic network $[7,14]$. These three primary objectives are important to define for diagnostic network analysis and can be evaluated pre- and post-optimization:

- Effectiveness: An effective diagnostic network should ensure that essential diagnostics are available, accessible, return results within clinically relevant turnaround times, and are of high quality. These are intermediate outcomes; final health outcomes in terms of the impact of a diagnostic network on public health and disease surveillance are not measured here.

Are essential diagnostics available to those who need them? This is measured by whether the tests are available geographically onsite, or via a referral system, and if so, if there is sufficient capacity. It can be measured as the number of health facilities that offer a given diagnostic onsite (or via a referral system) divided by the total number of health facilities in a country, weighted by facility volume. Integration of testing on a platform might increase the availability of certain diagnostic tests.

Are essential diagnostic services accessible to those who need them? Accessibility can be measured as the number of people who receive a given diagnostic divided by the total number of people estimated to require a given diagnostic across a specified time period.

Are essential diagnostic results returned in a timely manner? Access can be further qualified to include turnaround time - the proportion of diagnostic services that is accessible within a prescribed turnaround time period. Turnaround time can be measured as the amount of time taken between specimen collection to return of results at the requesting facility.

Are the diagnostic services available of high quality? Quality of the diagnostic services is measured based on the probability that the test result is reproducible and accurate. This is a function of good manufacturing practice, trained and competent staff following standard testing procedures, low specimen-rejection rates, and internal and external quality assurance.

- Efficiency: Efficiency of the diagnostic network can be measured in several ways: (1) cost outcomes: the ratio of financial resources consumed (testing costs incurred) and the output (number of tests completed) to determine a cost per test completed, and / or the cost per correct test result returned to the patient; (2) Device utilization: how efficiently a device is operated, measured as the average number of tests conducted on a piece of laboratory equipment divided by the maximum number of tests that can be conducted on that piece of laboratory equipment across a specified time period. Higher device utilization and testing integration frequently result in a lower cost per test [21]. The focus is on overall efficiency of the entire network and not individual devices.

- Adaptability: Adaptability measures the ability of a diagnostic network to meet current testing demands (effectiveness) and to adjust to changing needs within the diagnostic network, whether as a result of the addition of a disease program or specimen type, introduction of new technology, or a disease outbreak [14]. Both the Ebola outbreak of 2014/2015 and the current SARS-CoV-2 pandemic have highlighted the need to ensure that robust integrated systems and platforms are in place to enable an effective public health response. Adaptability is more difficult to measure as it includes factors not reflected in the diagnostic network (for example, leadership). A proxy for adaptability would be to assess the extent to which volumes of currently supported diagnostic tests were impacted by the changing needs within the diagnostic network (e.g., disease outbreak) or how quickly new technology can be adopted and successfully deployed within the network. DNO is a key process to be used to 
stress-test the diagnostic network to determine how well it can withstand shocks (for example, where underutilized devices can be relocated, or where spare capacity or integrated testing can be leveraged), or how best to adopt new technology.

\section{Conclusions}

Diagnostic network design and planning have, to date, predominantly used manual methods, with limited application of data analytics. Use of a DNO approach that can integrate multiple data inputs and constraints holds promise to improve network design, aimed at enhancing the efficiency, effectiveness, and adaptability of diagnostic networks, thereby improving public health and disease surveillance. This review aimed to clarify the terms and process commonly used in DNO. Using uniform language will contribute to establishing an evidence base on the effectiveness of DNO in the future.

Author Contributions: Conceptualization, K.N. and H.A.; writing-original draft preparation, K.N., S.J.G., H.A., B.E.N.; writing-review and editing, K.N., S.J.G., H.A., B.E.N., K.T.L.S., M.B., A.I., P.O., A.B.T., K.K., S.C.; project administration, K.K.; funding acquisition, S.C., K.K., H.A. All authors have read and agreed to the published version of the manuscript.

Funding: This research was supported by the Bill \& Melinda Gates Foundation through a grant to FIND (OPP1203377).

Institutional Review Board Statement: Not Applicable.

Informed Consent Statement: Not Applicable.

Data Availability Statement: No new data was created or analyzed in this study. Data sharing is not applicable to this article.

Conflicts of Interest: The authors declare no conflict of interest. The funders had no role in the in the study design, analysis, decision to publish, or preparation of the manuscript. The authors' views expressed in this publication do not necessarily reflect the views of the Bill \& Melinda Gates Foundation.

\section{References}

1. Access to Diagnostics-Fondation Mérieux USA. Available online: https://www.fondation-merieuxusa.org/access-todiagnostics (accessed on 22 October 2020).

2. The Lewin Group; Wolcott, J.; Schwartz, A.; Goodman, C. Laboratory Medicine: A National Status Report. 2008. Available online: https:/ / www.cdc.gov/labbestpractices / pdfs/2007-status-report-laboratory_medicine_-_a_national_status_report_from_ the_lewin_group_updated_2008-9.pdf (accessed on 23 October 2020).

3. World Health Organization. Second WHO Model List of Essential In Vitro Diagnostics. Who/Mvp/Emp/201905. 2019. Available online: https:/ / www.ghdonline.org/uploads/EDL_ExecutiveSummary_15may.pdf (accessed on 23 October 2020).

4. World Health Organization (WHO). International Health Regulations (2005) Third Edition. 2016. Available online: https: //www.who.int/publications/i/item/9789241580496 (accessed on 23 October 2020).

5. Petti, C.A.; Polage, C.R.; Quinn, T.C.; Ronald, A.R.; Sande, M.A. Laboratory medicine in Africa: A barrier to effective health care. Clin. Infect. Dis. 2006, 377-382. [CrossRef] [PubMed]

6. Nkengasong, J.N.; Yao, K.; Onyebujoh, P. Laboratory medicine in low-income and middle-income countries: Progress and challenges. Lancet 2018, 1873-1875. [CrossRef]

7. Alemnji, G.; Peter, T.; Vojnov, L.; Alexander, H.; Zeh, C.; Cohn, J.; Watts, D.H.; de Lussigny, S. Building and Sustaining Optimized Diagnostic Networks to Scale-up HIV Viral Load and Early Infant Diagnosis. J. Acquir. Immune. Defic. Syndr. 2020, 84, S56-S62. [CrossRef]

8. Best, M.; Sakande, J. Practical recommendations for strengthening national and regional laboratory networks in Africa in the Global Health Security era. Afr. J.Lab. Med. 2016, 5, 1-10. [CrossRef] [PubMed]

9. US Centers for Disease Control and Prevention. Consultation on Technical and Operational Recommendations for Clinical Laboratory Testing Harmonization and Standardization. Available online: https://www.who.int/healthsystems/round9_9.pdf (accessed on 23 October 2020).

10. World Health Organisation. The Maputo Declaration on Strengthening of Laboratory Systems. Available online: https://www. who.int/diagnostics_laboratory/procurement/Maputo-Declaration_2008_2.pdf?ua=1 (accessed on 23 October 2020).

11. African Society for Laboratory Medicine. Freetown Declaration-African Society for Laboratory Medicine. Available online: https:/ / aslm.org/what-we-do/freetown-declaration/ (accessed on 16 October 2020). 
12. Ondoa, P.; Ndlovu, N.; Keita, M.-S.; Massinga-Loembe, M.; Kebede, Y.; Odhiambo, C.; Mekonen, T.; Ashenafi, A.; Kebede, A.; Nkengasong, J. Preparing national tiered laboratory systems and networks to advance diagnostics in Africa and meet the continent's health agenda: Insights into priority areas for improvement. Afr. J.Lab. Med. 2020, 9, 1-10. [CrossRef] [PubMed]

13. World Health Organization (WHO). Manual for Procurement of Diagnostics and Related Laboratory Items and Equipment. 2013. Available online: http://www.who.int/about/licensing/copyright_form/en/index.html (accessed on 23 October 2020).

14. Piatek, A. Tuberculosis Diagnostic Networks: Moving Beyond the Laboratory to End Tuberculosis in Africa. Available online: https:/ / ajlmonline.org/index.php/ajlm/article/view/608/785 (accessed on 2 November 2020).

15. Cairncross, S.; Periès, H.; Cutts, F. Vertical health programmes. Lancet 1997, 349, S20-S21. [CrossRef]

16. World Health Organization (WHO). Molecular diagnostics Integration Global Meeting Report; WHO: Geneva, Switzerland; Available online: https:/ / apps.who.int/iris/handle/10665/331708 (accessed on 23 October 2020).

17. The World Health Organisation. Everybody Business: Strengthening Health Systems to Improve Health Outcomes: WHO's Framework for Action; WHO: Geneva, Switzerland, 2007.

18. Evans, D.B.; Hsu, J.; Boerma, T. Universal Health Coverage and Universal Access. Bulletin of the World Health Organization; WHO: Geneva, Switzerland, 2013.

19. Hawkins, R.C. Laboratory Turnaround Time Robert. Clin. Biochem. Rev. 2018, 28, 179-194.

20. Albert, H.; Purcell, R.; Wang, Y.Y.; Kao, K.; Mareka, M.; Katz, Z.; Llang Maama, B.; Mots'oane, T. Designing an optimized diagnostic network to improve access to TB diagnosis and treatment in Lesotho. PLoS ONE 2020, 15, e0233620. [CrossRef] [PubMed]

21. Girdwood, S.J.; Nichols, B.E.; Moyo, C.; Crompton, T.; Chimhamhiwa, D.; Rosen, S. Optimizing viral load testing access for the last mile: Geospatial cost model for point of care instrument placement. PLoS ONE 2019, 14, e221586. [CrossRef] [PubMed]

22. Nichols, B.E.; Girdwood, S.J.; Crompton, T.; Stewart-Isherwood, L.; Berrie, L.; Chimhamhiwa, D.; Moyo, C.; Kuehnle, J.; Stevens, W.; Rosen, S. Impact of a borderless sample transport network for scaling up viral load monitoring: Results of a geospatial optimization model for Zambia. J. Int. AIDS Soc. 2018, 12, e25206. [CrossRef] [PubMed]

23. Kiyaga, C.; Sendagire, H.; Joseph, E.; McConnell, I.; Grosz, J.; Narayan, V.; Esiru, G.; Elyanu, P.; Akol, Z.; Kirungi, W.; et al. Uganda's new national laboratory sample transport system: A successful model for improving access to diagnostic services for early infant HIV diagnosis and other programs. PLoS ONE 2013, 8, e78609. [CrossRef] [PubMed]

24. Nichols, B.E.; Girdwood, S.J.; Shibemba, A.; Sikota, S.; Gill, C.J.; Mwananyanda, L.; Noble, L.; Isherwood-Stewart, L.; Scott, L.; Carmona, S.; et al. Cost and Impact of Dried Blood Spot Versus Plasma Separation Card for Scale-up of Viral Load Testing in Resource-limited Settings. Clin. Infect. Dis. 2020, 70, 1014-1020. [CrossRef] [PubMed]

25. Wang, Z.; Yan, R.; Hollister, K.; Xing, R. A Relative Comparison of Leading Supply Chain Management Software Packages. Int. J. Inf. Syst. Supply Chain Manag. 2009, 2, 81-96. [CrossRef]

26. Glencross, D.K.; Coetzee, L.M.; Cassim, N. An Integrated Tiered Service Delivery Model (ITSDM) Based on Local CD4 Testing Demands Can Improve Turn-Around Times and Save Costs whilst Ensuring Accessible and Scalable CD4 Services across a National Programme. PLoS ONE 2014, 9, e114727. [CrossRef] [PubMed]

27. Nichols, B.E.; Girdwood, S.J.; Crompton, T.; Stewart-Isherwood, L.; Berrie, L.; Chimhamhiwa, D.; Moyo, C.; Kuehnle, J.; Stevens, W.S.; Rosen, S.; et al. Monitoring viral load for the last mile: What will it cost? J. Int. AIDS Soc. 2019, 22, e25337. [CrossRef] [PubMed]

28. Ogoro, J. Designing Optimal Integrated Sample Referral Systems in Kenya. The 50th Union World Conference on Lung Health, Hyderabad, India. Available online: https:/ / www.finddx.org/wp-content/uploads/2019/12/04-Dx-network-optimization_ SRS-Kenya_JeremiahOgoro_Union_310CT19.pdf (accessed on 23 October 2020).

29. Ogoro, J. Diagnostic Network Optimization as Part of a Data-Driven National Strategic Planning Process in Kenya. The 50th Union World Conference on Lung Health, Hyderabad, India. Available online: https:/ /www.finddx.org/wp-content/uploads / 2019/12/02-DX-network-optimization_Kenya_JeremiahOgoro_Union_31OCT19.pdf (accessed on 23 October 2020).

30. Sistoso, E.V. Placing Diagnostic Devices for Impact: Experience of the Philippines. The 50th Union World Conference on Lung Health, Hyderabad, India. Available online: https:/ / www.finddx.org/wp-content/uploads/2019/12/03-Placing-DiagnosticDevices-for-Impact_Philippines_EddieSistoso_Union_31OCT19.pdf (accessed on 23 October 2020).

31. Llamasoft: Supply Chain Guru. Llamasoft Inc. Available online: https://llamasoft.com (accessed on 23 October 2020).

32. PEPFAR Zambia Country Operational Plan 2019 Strategic Direction Summary; PEPFAR: Washington, DC, USA, 2019.

33. Girdwood, S.J.; Crompton, T.; Sharma, M.; Dorward, J.; Garrett, N.; Drain, P.K.; Stevens, W.S.; Nichols, B.E. Cost-effectiveness of adoption strategies for point of care HIV viral load monitoring in South Africa. EClinical Med. 2020, 28, 100607. [CrossRef] [PubMed]

34. Girdwood, S.J.; Crompton, T.; Olsen, F.; Sejake, P.; Cassim, N.; Diallo, K. Delaying courier specimen collection time improves patient access to viral load testing. In Proceedings of the International AIDS Conference, Virtual, 6-10 July 2020.

35. Llamasoft: OptiDx. Llamasoft Inc, FIND, GHSC-PSM. Available online: finddx.org/access/dx-network/opt/ (accessed on 23 October 2020).

36. Purcell, R.; Albert, H.; Building an Open Access Software Tool to Allow Countries to Design Patient-Centered and CostEffective Diagnostic Networks. Global Health Supply Chain Summit. Available online: https://slideplayer.com/slide/17812219/ (accessed on 23 October 2020). 
37. Albert, H. Networks for Optimized Diagnosis to End TB: What Is It and What Can It Do? The 50th Union World Conference on Lung Health, Hyderabad, India. Available online: www.finddx.org (accessed on 23 October 2020). 